\title{
Salter Harris Type II Physeal Ankle Fracture: A review of 10 cases
}

\author{
by J. Terrence Jose Jerome, MBBS, DNB (Ortho), MNAMS (Ortho) ${ }^{1 凶}$, \\ Mathew Varghese, M.S. (Ortho) ${ }^{2}$, Balu Sankaran, FRCS (C) ${ }^{3}$, FAMS, K. Thirumagal, MD $^{4}$
}

The Foot and Ankle Online Journal 3 (7): 2

Salter Harris Type II ankle injuries are reviewed in 10 cases. Potential premature physeal closure (PPC) is a real complication in most open reductions of this fracture. In the cases presented here, closed reduction offered the best clinical outcomes with no evidence of premature physeal closure. Restoring the congruency of the physeal plate is imperative in preventing long term complications such as talar tilts, post traumatic ankle stiffness and other angular and limb length discrepancies.

Key words: Salter Harris Fracture, ankle fracture.

\author{
Accepted: June, $2010 \quad$ Published: July, 2010
}

This is an Open Access article distributed under the terms of the Creative Commons Attribution License. It permits unrestricted use, distribution, and reproduction in any medium, provided the original work is properly cited. (The Foot and Ankle Online Journal (www.faoj.org)

I njuries to the distal tibial and fibular physis are generally reported to account $25 \%$ to $38 \%$ of all physeal fractures, second in frequency only to distal radial physeal fractures. ${ }^{1}$ In skeletally immature individuals, physeal ankle fractures are slightly more common than fractures of the tibial or fibular diaphysis. $^{2} \quad$ Up to $58 \%$ of physeal ankle fractures occur during sports activities and account for 10 to $40 \%$ of all injuries to skeletal immature atheletes. ${ }^{3}$ Physeal ankle fractures are more common in males than females. Tibial physeal fractures most commonly occur between the ages of 8 and 15 years, and fibular fractures between the ages of 8 and 14 years. ${ }^{4}$ In 1898, Poland in his monograph, pointed out that in children, ligaments are stronger than physeal cartilage and forces that result in ligament damage in adults cause fractures of the physis in children. ${ }^{5}$

Address correspondence to: Dr. J. Terrence Jose Jerome, MBBS.,DNB (Ortho), MNAMS (Ortho), FNB (Hand \& Microsurgery). E-mail:

terrencejose@gmail.com

\footnotetext{
${ }^{1}$ Registrar in Orthopedics, Dept. of Orthopedics, St. Stephen's Hospital, Tiz Hazari, Delhi 54, India.

${ }^{2}$ Registrar in Orthopedics, Department of Orthopedics, St. Stephens Hospital, Tiz Hazari, Delhi, India.

${ }^{3}$ Head Professor, Department of Orthopedics, St. Stephens Hospital, Tiz Hazari, Delhi, India.

${ }^{4}$ Professor Orthopedics, Tamilu,India.
}

The various patterns of injury can be better understood if one is aware of the direct and indirect forces that act on the ankle, the ligamentous anatomy of the ankle, and the effects of trauma on the epiphysis before and during the time of epiphyseal fusion. A characteristic radiographic pattern of injury occurs as a result of each particular injuring force, which in turn requires a specific mode of fracture reduction. We present our cases with management protocol and review of the literature.

\section{Materials and methods}

This is retrospective study conducted from January 2003 to December 2005. A Salter-Harris Type II injury is an epiphyseal separation with a metaphyseal fragment attached to the epiphysis. Notation was made in each case as to the age of the patient, gender, mode of injury, mechanism of injury, methods of treatment, complications associated fractures of the fibula, and follow-up to 2 years duration. 


\begin{tabular}{|c|c|c|c|c|c|c|c|c|c|c|}
\hline Case & Age & Side & $\begin{array}{l}\text { Mode of } \\
\text { Injury }\end{array}$ & $\begin{array}{l}\text { Vascular } \\
\text { Status }\end{array}$ & $\begin{array}{l}\text { Mech. of } \\
\text { Injury }\end{array}$ & Closed Reduction & ORIF & $R O M$ & Complications & $P P C^{*}$ \\
\hline 1 & $8 \mathrm{M}$ & L & $\begin{array}{l}\text { Fall from } \\
\text { stairs }\end{array}$ & Intact & PER & Unstable & $\begin{array}{l}\text { Transmetaphyeal } \\
\text { screws (2) }\end{array}$ & $\begin{array}{l}30^{\circ} \\
\text { Reduction } \\
\text { in both } \\
\text { DF\&PF }\end{array}$ & $\begin{array}{l}12^{\circ} \text { valgus tilt, } \\
\text { ST and } \\
\text { periosteum } \\
\text { interposition }\end{array}$ & Yes \\
\hline 2 & $10 \mathrm{M}$ & L & $\begin{array}{l}\text { Fall from } \\
\text { stairs }\end{array}$ & $\begin{array}{l}\text { Not Felt } \\
\text { (swelling) }\end{array}$ & SER & Stable & - & $\begin{array}{l}\text { Severe } \\
\text { restriction } \\
\text { of DF\&PF }\end{array}$ & $\begin{array}{l}\text { Prolonged } \\
\text { immobilization }\end{array}$ & No \\
\hline 3 & $11 \mathrm{~F}$ & $\mathrm{R}$ & $\begin{array}{l}\text { Fall from } \\
\text { height }\end{array}$ & $\begin{array}{l}\text { Not Felt } \\
\text { (swelling) }\end{array}$ & PER & Unstable & $\begin{array}{l}\text { Transmetaphyeal } \\
\text { screws (2) }\end{array}$ & $\begin{array}{l}15^{\circ} \\
\text { Reduction } \\
\text { in both } \\
\text { DF\&PF }\end{array}$ & $\begin{array}{l}12^{\circ} \text { valgus tilt, } \\
\mathrm{ST} \text { interposition }\end{array}$ & No \\
\hline 4 & $13 \mathrm{~F}$ & $\mathrm{R}$ & $\begin{array}{l}\text { Football } \\
\text { Injury }\end{array}$ & Intact & SPF & Unstable & $\begin{array}{l}\text { Anterior to } \\
\text { posterior } \\
\text { transmetaphyeal } \\
\text { screws (2) }\end{array}$ & $\begin{array}{l}\text { Severe } \\
\text { restriction } \\
\text { of DF }\end{array}$ & $\begin{array}{l}\text { Soft tissue and } \\
\text { periosteal } \\
\text { interposition }\end{array}$ & Yes \\
\hline 5 & $10 \mathrm{M}$ & L & $\begin{array}{l}\text { Fall from } \\
\text { stairs }\end{array}$ & Intact & SER & Stable & - & Normal & - & No \\
\hline 6 & $9 \mathrm{~F}$ & $\mathrm{R}$ & $\begin{array}{l}\text { Football } \\
\text { Injury }\end{array}$ & $\begin{array}{l}\text { Not Felt } \\
\text { (swelling) }\end{array}$ & PER & Unstable & $\begin{array}{l}\text { Transmetaphyeal } \\
\text { screws (2) }\end{array}$ & $\begin{array}{l}\text { Severe } \\
\text { restriction } \\
\text { of both } \\
\text { DF\&PF }\end{array}$ & $10^{\circ}$ valgus tilt & No \\
\hline 7 & $9 \mathrm{~F}$ & L & $\begin{array}{l}\text { Fall from } \\
\text { bicycle }\end{array}$ & Intact & PER & Unstable & $\begin{array}{l}\text { Transmetaphyeal } \\
\text { screws (2) }\end{array}$ & $\begin{array}{l}30^{\circ} \\
\text { Reduction } \\
\text { in both } \\
\text { DF\&PF }\end{array}$ & $\begin{array}{l}10^{\circ} \text { valgus tilt, } \\
\mathrm{ST} \text { and } \\
\text { periosteum } \\
\text { interposition }\end{array}$ & Yes \\
\hline 8 & $12 \mathrm{M}$ & $\mathrm{R}$ & $\begin{array}{l}\text { Fall from } \\
\text { stairs }\end{array}$ & Intact & SER & Stable & - & Normal & - & No \\
\hline 9 & $11 \mathrm{M}$ & $\mathrm{R}$ & $\begin{array}{l}\text { Fall from } \\
\text { stairs }\end{array}$ & Intact & SER & Stable & - & Normal & - & No \\
\hline 10 & $13 \mathrm{M}$ & $\mathrm{R}$ & $\begin{array}{l}\text { Fall in } \\
\text { bathroom }\end{array}$ & $\begin{array}{l}\text { Not Felt } \\
\text { (swelling) }\end{array}$ & SPF & Unstable & $\begin{array}{l}\text { Transmetaphyeal } \\
\text { screws (2) }\end{array}$ & $\begin{array}{l}\text { Severe } \\
\text { restriction } \\
\text { of both } \\
\text { DF\&PF }\end{array}$ & $\begin{array}{l}\text { Soft tissue and } \\
\text { periosteal } \\
\text { interposition }\end{array}$ & Yes \\
\hline
\end{tabular}

Table 1 Ten case presentations of Salter-Harris Type II physeal fracture. Four cases of stable closed reduction resulted in normal range of motion and no premature physeal closure (PPC*). Four other cases of open reduction internal fixation (ORIF) resulted in premature physeal closure. ( $F$ - Female, $M$ - Male, L - Left, R - Right, PER - Pronation, eversion, external rotation, SER - Supination, external rotation, SPF - Supination plantarflexion, DF - dorsiflexion, PF plantarflexion).

The cases were also examined according to mechanism of injury using the system described by Crenshaw. ${ }^{8}$ This system describes mechanisms of injury; plantarflexion, external rotation, abduction, adduction, and direct injury/axial compression. (Table 1).

\section{Case Examples}

\section{Case 1}

This 11 year-old girl sustained a fall from height and injured her right ankle. Diffuse swelling, tenderness, redness were the initial findings.

(C) The Foot and Ankle Online Journal, 2010
It was a severely displaced eversion, pronationexternal rotation (PER) injury. Radiograph showed severe displacement of fracture fragments. (Figs. 1A and B) Closed reduction was unsuccessful and a valgus tilt of the ankle mortise was noted.

Open reduction and internal fixation (ORIF) was planned under spinal anesthesia. Soft tissue was interposed laterally between the metaphyseal fragments and the distal tibia. Reduction was completed and stabilized with two transmetaphyseal cancellous screws placed above the physis. (Fig. 2) At the end of 2 years, she had mild restriction of ankle range of motion and had valgus tilt which corrected spontaneously over time. She can do her normal activities. 

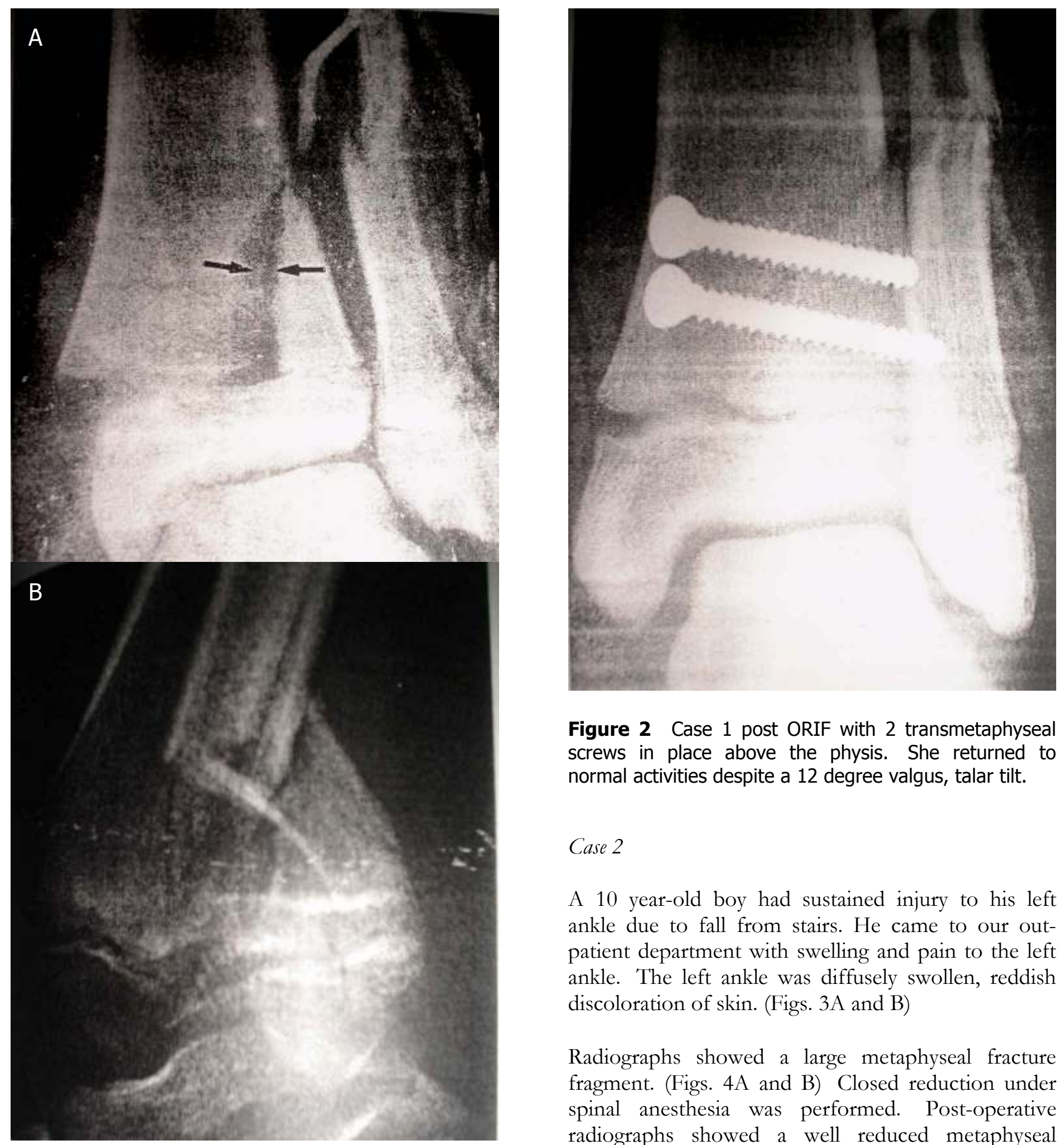

Figure 2 Case 1 post ORIF with 2 transmetaphyseal screws in place above the physis. She returned to normal activities despite a 12 degree valgus, talar tilt.

\section{Case 2}

A 10 year-old boy had sustained injury to his left ankle due to fall from stairs. He came to our outpatient department with swelling and pain to the left ankle. The left ankle was diffusely swollen, reddish discoloration of skin. (Figs. 3A and B)

Radiographs showed a large metaphyseal fracture fragment. (Figs. 4A and B) Closed reduction under spinal anesthesia was performed. Post-operative radiographs showed a well reduced metaphyseal fragment. (Figs.5A and B)

Figure 1A and B Case 1 demonstrates a severe eversion, pronation-external rotation (PER) injury after falling from a height. 


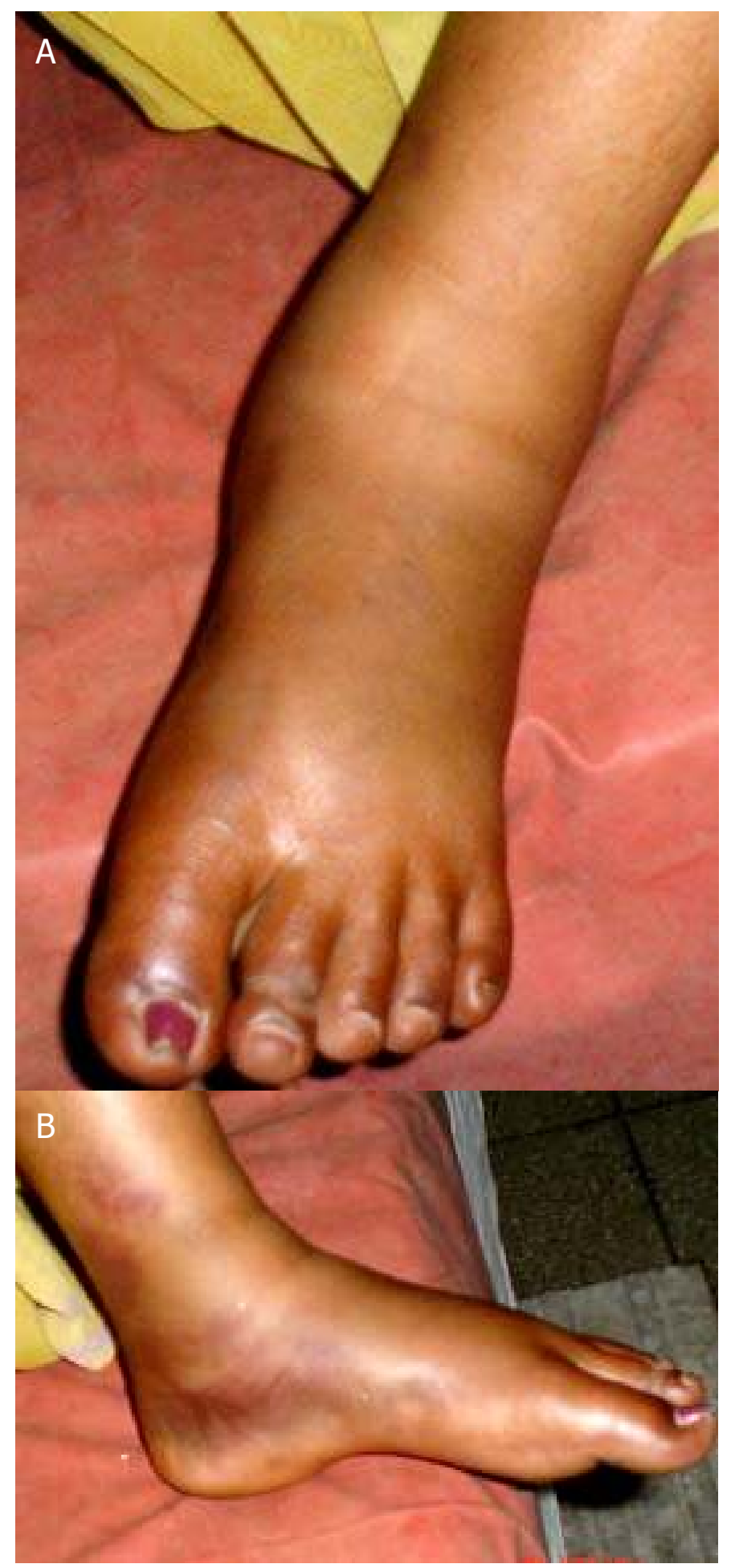

Figure 3A and B Case 2 shows typical ecchymosis and swelling to the foot and ankle following a SalterHarris type II physeal ankle fracture.

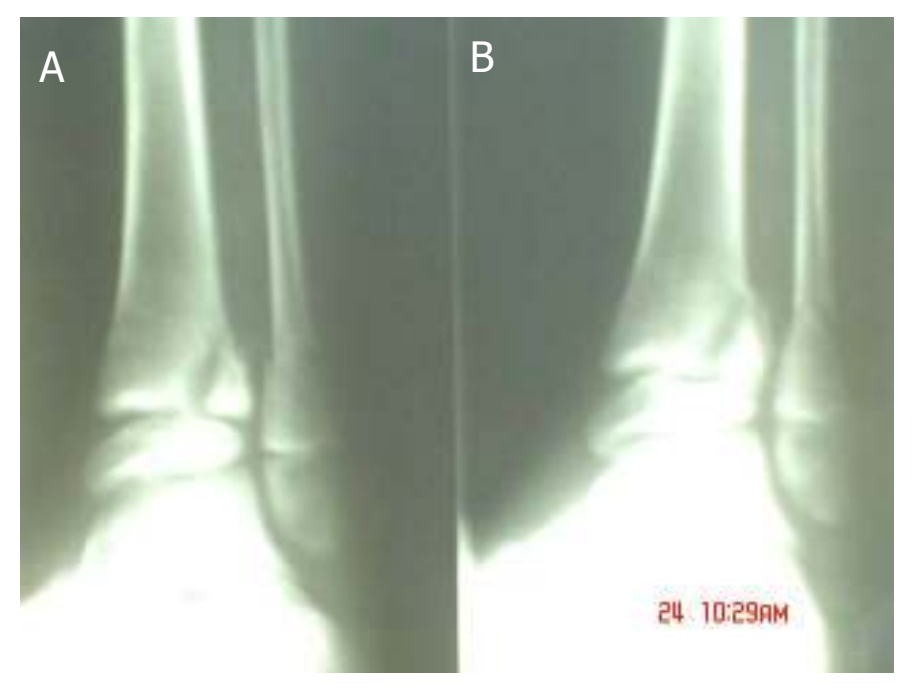

Figure 4A and B Case 2 shows large metaphyseal fracture after a fall from the stairs. This was a relatively stable supination-external rotation (SER) injury.

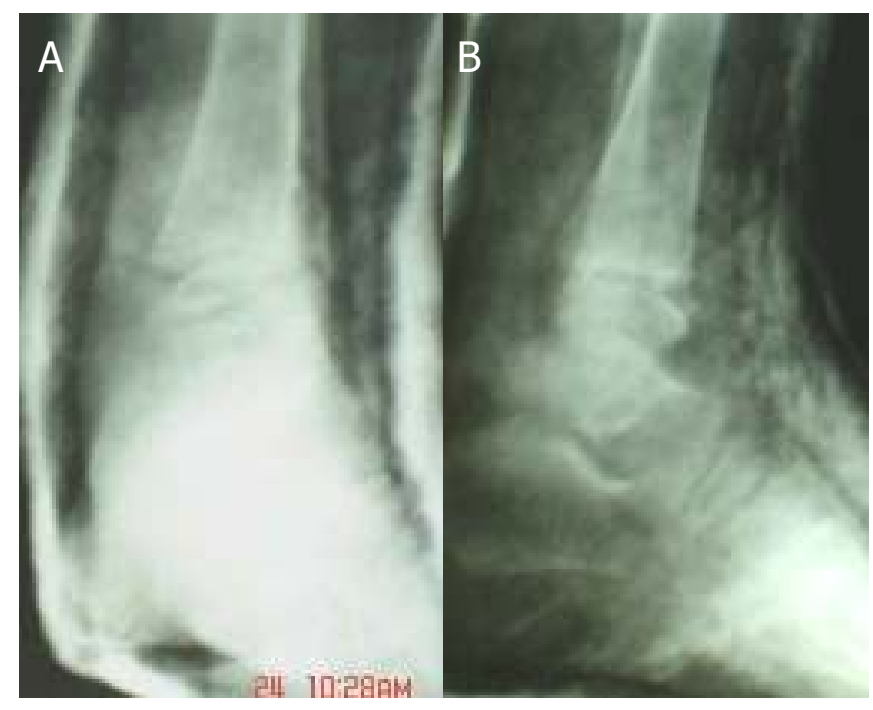

Figure 5A and B Case 2 shows a stable ankle mortise after successful closed reduction.

An above-knee cast was applied for 4 weeks. It was then changed to below-knee for a period of 4 weeks. A follow-up radiograph was obtained every month for 2 years or until Park-Harris growth arrest line parallel to the physis is visible and there is no evidence of physeal deformity. The patient has full range of motion and is doing all of his daily activities. (Figs 6A, B and C) 


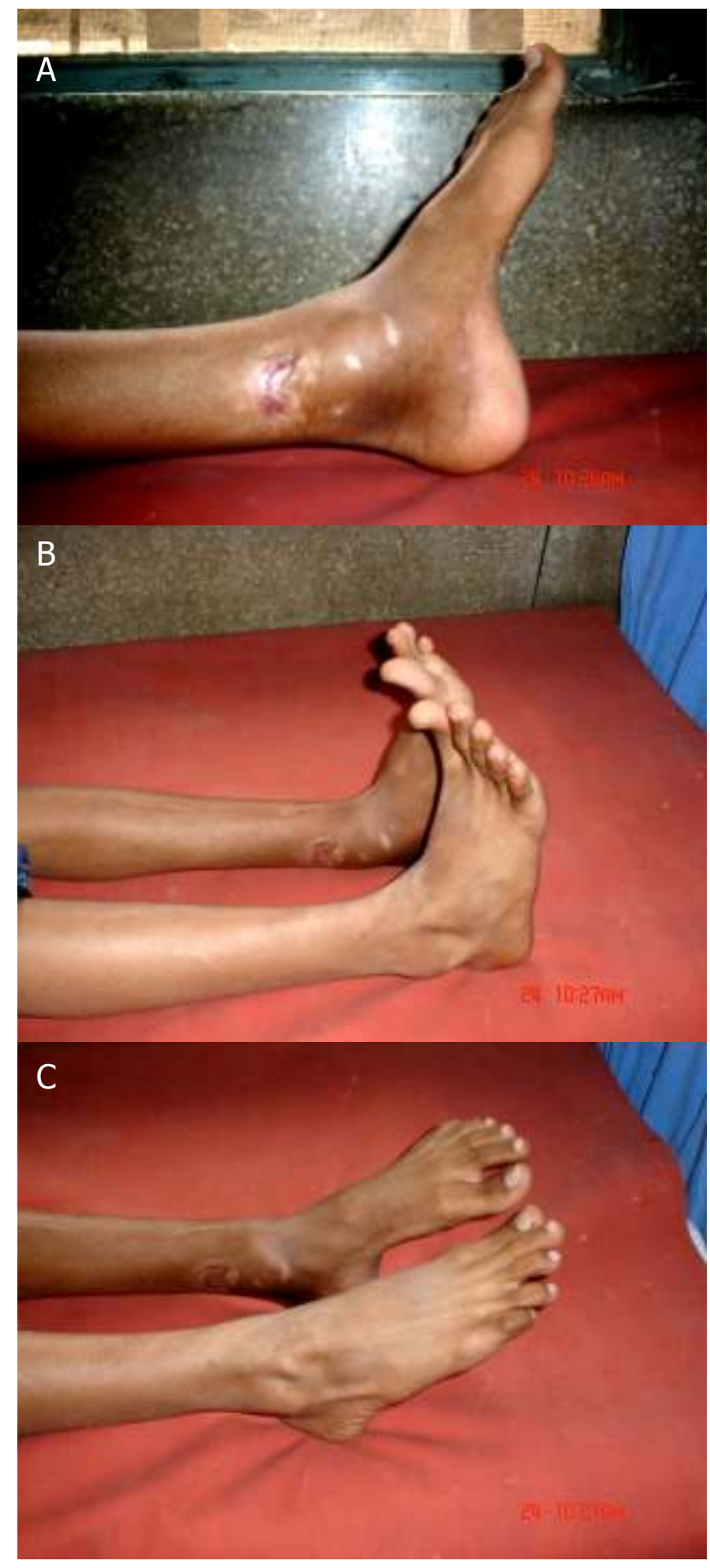

Figures 6A, B and C Case 2 shows a stable ankle mortise after successful closed reduction with full range of motion.

\section{Results}

Our patients were between 8 and 14 years old. There were 6 males and 4 females examined. Equal number of sides was involved. The average age was 10.6 years. All had suffered the fracture following a severe type of injury. Forty percent of the patients on presentation had diffuse swelling where the vascular status could not be properly documented due to severe pain. The most common mechanism of injury pattern was supination-external rotation (SER) and pronation-eversion-external rotation (PER) (40\% each). Supination-plantar flexion (pure posterior displacement and posterior metaphyseal fragment, Greenstick distal fibula fracture) accounted for $20 \%$ of the fracture pattern. All supination-external rotation was treated by closed reduction under spinal anesthesia and they remained very stable in the follow up. All pronation-eversion-external rotation and supination-plantar flexion were unstable after closed reduction. They were treated by open reduction and internal fixation with 2 transmetaphyseal cancellous screws (above the physis). Antero-posterior screws for supination plantar flexion pattern and mediolateral for pronation-external rotation injuries were done. Soft tissue interposition, periosteum interposition were the most commonly interpreted structures found in the open reduction in PER and SPF fractures. Range of motion was severely restricted in $20 \%$ of patients (one each of SPF and PER type). All PER type of injury had valgus tilt of an average of 11 degree in the initial post-operative period. There was no residual angulation in their long term follow up as this had spontaneously corrected. Premature physeal closure was seen in all cases of PER and SPF types. No premature physeal closure was seen in the supination and external rotation injury pattern.

\section{Discussion}

In 1922, Ashhurst and Bromer published a thorough review of the literature and the results of their own extensive investigations and described a classification of ankle injuries based on the mechanism of injury. ${ }^{6}$ 


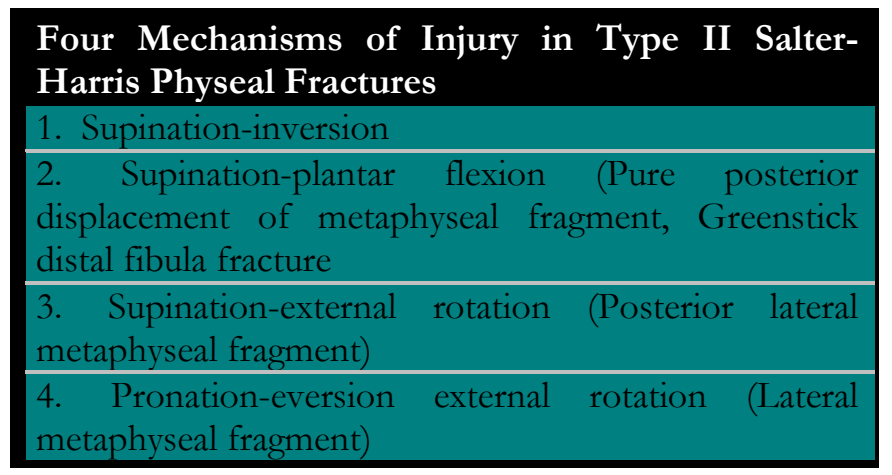

Table 2 The 4 mechanisms of injury in Type II SalterHarris Physeal Fractures.

This classification did not differentiate between ankle injuries in adults and those of children. In 1955, Caruthers and Crenshaw reported 54 ankle physeal fractures, which were classified according to their modification of Asshurst. ${ }^{8}$ They confirmed that growth-related deformities were frequent after SalterHarris type III and IV injuries and infrequent after fractures caused by external rotation, abduction, and plantarflexion (Salter type II injuries). Spiegel and colleagues reviewed 237 physeal fractures and reported a high incidence of growth abnormalities after Salter-Harris III and IV injuries. Most of these patients had only mild shortening, but 6 had angular deformities that did not correct with growth. ${ }^{4}$ Based on the results of 65 physeal ankle fractures, Kling and Co-workers concluded that frequency of growth related deformities could be reduced by open reduction and internal fixation of Salter-Harris III and IV fractures.

Appropriate treatment of ankle fractures in children depends on the location of the fracture, the degree of displacement, and the age of the child. Nondisplaced fractures may be appropriate for displaced fractures; if the closed fractures cannot be maintained with casting, skeletal fixation is necessary. If closed reduction is not possible, open reduction is indicated, provided there is significant physeal or articular displacement, followed by internal fixation or cast immobilization.
The anatomic type of the fracture (usually defined by the Salter-Harris classification), the mechanism of injury, and the amount of displacement of the fragments are the most important considerations of treatment.

When the articulation is disrupted, the amount of articular step-off or separation must be measured. The neurovascular status of the limb or the status of the skin may require emergency treatment of the fracture and associated problems. The general health of the patient and the time since injury also must be considered.

Type II Salter-Harris physeal fractures can be caused by four mechanisms. (Table 2) Patients with significant displaced fractures have severe pain and obvious deformity. The position of the foot relative to the leg may provide important information about the mechanism of injury and should be considered in reduction. The status of the skin, pulses, sensory and motor function should be determined and recorded. Tenderness, swelling, and deformity of the ipsilateral leg should be noted. Patients with non-displaced or minimally displaced ankle fractures often have no deformity, minimal swelling and moderate pain. Because of their benign clinical appearance, such fractures may be easily missed if radiographs are not obtained. On a standard antero-posterior view, the lateral portion of the distal physis is often partially obscured by the distal fibula.

A high quality mortise view of the ankle is essential in addition to the normal views. ${ }^{9}$ Computerized tomography (CT) is useful in the evaluation of the intra-articular fractures, especially the Tillaux and triplane fractures. ${ }^{10}$ Magnetic resonance imaging (MRI) is occasionally helpful in the identification of osteochondral injuries to the joint surfaces in children with ankle fractures. ${ }^{11}$

The location of Thurston-Holland fragment is helpful in determining the mechanism of injury in addition to the direction of displacement of the distal tibial epiphysis and associated fibular fracture: 
1) A lateral fragment indicates pronation-eversionexternal rotation. 2) a poster-medial fragment indicates supination-external rotation and 3) a posterior placed fragment indicates supination-plantar flexion injury.

Our results showed that the injury most commonly occurs between the age of 8 and 13 years because of direct and indirect forces that act on the ankle, the ligamentous anatomy of the ankle, and the effects of trauma on the epiphysis before and during the time of epiphyseal fusion. The mode of injury remained the high-energy type and severe displacement is always associated with diffuse swelling. This swelling prompted to check for the distal pulses and toe movements. The capillary circulation and sensation was intact in all of them. None of our patients had sustained neurovascular injury in this type of physeal fractures. Salter and Harris type II injury can be cause by any of the four mechanism described. ${ }^{14}$ PER and SER injury remained the most commonly involved mechanism in our pediatric ankle fractures.

Non-displaced fractures can be treated with cast immobilization usually with an above-knee cast for 3 to 4 weeks, followed by a below-knee walking cast for another 3 to 4 weeks. All supination and external rotation injuries in our study were stable after closed reduction and were treated with cast immobilization. One patient needed prolonged immobilization (12 weeks) because of poor compliance and he developed severe ankle stiffness. Although most researchers agree that closed reduction of significantly displaced Salter Harris type II ankle fracture should be attempted, opinions differ as to what degree of residual displacement or angulation is unacceptable and requires open reduction. Based on the follow-up of 33 cases, Caruthers concluded that 'accurate reposition of the displaced epiphysis at the expense of forced or repeated manipulation or operative intervention is not indicated since spontaneous realignment of the ankle occurs even late in the growing period'. They found no residual angulation at follow up in patients who had up to 12 degrees of tilt after reduction, even in patients as old as 13 years at the time of injury.
An 11 degree valgus tilt was seen in pronation and external rotation type of injury in our study. The entire patient showed spontaneous realignment in their 2 years follow-up irrespective of the age of the patient.

Speigel and associates recommended from their series that 'precise anatomic reduction' is essential to prevent angular deformities. ${ }^{4}$ Incomplete reduction is usually caused by interposition of soft tissue including the neurovascular bundle, resulting in circulatory embarrassment when closed reduction was attempted. A less definitive indication for open reduction is interposition of the periosteum, which causes physeal widening with no angulation or with minimal angulation. $^{15}$

PER and supination-flexion injury in our cases reported here were invariably unstable after closed reduction because of the severity of injury, displacement and soft tissue and periosteum interposition. Good results were obtained after open reduction and extraction of the periosteal flap. It is not clear that failure to extract the periosteum in such cases results in problems sufficient to warrant operation.

Due to the fear of iatrogenic damage to the distal tibial physis during closed reduction, many researchers recommend the use of general anesthesia with adequate muscle relaxation. However, no reports have compared the frequency of growth abnormalities in patients with after these fractures were reduced. We have reduced our SER injuries under spinal anesthesia and found the reduction stable and easy to perform. Hematoma block, intravenous sedation, intravenous regional anesthesia has been reported to be effective for pain relief in lower extremity injuries. ${ }^{16,17}$ All fractures were reduced with a single manipulation.

Reflex sympathy dystrophy occasionally develops after these injuries and is treated initially with an intensive formal physical therapy regimen that encourages range of motion exercises and weight bearing. ${ }^{12}$ 
Delayed union, growth arrest, arthritis, avascular necrosis of the distal epiphysis and non-union are rare after this type II physeal fractures. Rotational malunion usually occur after triplane fractures that are either incompletely reduced or are initially immobilized in below-knee casts. Anterior angulation or plantar flexion deformity usually occurs after supination-plantar flexion injuries. Two of our patients developed severe restriction of dorsiflexion at the end of one year. Range of motion improved at the end of 2 years due to the remodeling with growth.

Theoretically, an equines deformity might occur if the angulation exceeds the range of ankle dorsiflexion before fracture, but this is rare, probably because the deformity is in the plane of joint motion and tends to remodel with growth. Valgus deformity is most common after external rotation type II injuries. ${ }^{8}$

For the Salter Harris type II fractures of the distal tibial physis 39.6\% developed premature physeal closure. There is a difference in PPC based on injury mechanism. ${ }^{13}$ The rate of Premature Physeal Closure (PPC) in patients with a supination-external-rotationtype injury was $35 \%$, whereas patients with pronationabduction-type injuries developed PPC in 54\% of cases. ${ }^{13}$ Type of treatment may prevent PPC in some fractures. Forty percent of our patients had premature physeal closure. Twenty percent each of PER and supination plantar flexion injury showed premature closure. None of the supination and external rotation injury developed premature closure. The most important determinant of PPC is the fracture displacement following reduction.

\section{Conclusions}

Knowledge of common pediatric ankle fracture patterns and the pitfalls associated with their evaluation and treatment will aid the clinician in the effective management of these injuries. PPC is a common problem following Salter and Harris type II fractures of the distal tibia. Operative treatment may decrease the frequency of PPC in some fractures. Regardless of treatment method, we recommend anatomic reduction to decrease the risk of PPC.
The potential complications associated with pediatric ankle fractures include those seen with adult fractures (such as posttraumatic arthritis, stiffness, and reflex sympathetic dystrophy) as well as those that result from physeal damage (including leg-length discrepancy, angular deformity, or a combination thereof).

The goals of treatment are to achieve and maintain a satisfactory reduction and to avoid physeal arrest. In examining epiphyseal injuries of the ankle, the patterns of injury can easily be recognized and related to the mechanism of injury. Therefore, adequate therapeutic maneuvers can be instituted to restore the congruency of the epiphyseal plate. Adequate reduction of this fracture is necessary because it involves the joint surface. Being aware of the age incidence of these various fractures and recognizing the patterns of injury encountered and the subtle differences between various fractures, one can more accurately diagnose injuries of the distal tibia and direct the proper therapy.

Although most pediatric fractures do well, vigilance must be maintained because these injuries may have substantial long-term consequences. Angular deformity and joint incongruity can result in premature degenerative arthritis. Treatment strategies must be tailored to both the specific injury and the patient's skeletal maturity. Follow-up of physeal injuries must extend at least 6 months after the injury to be sure that the growth of the physis is symmetric.

\section{References}

1. Hynes D, O Brien T. Growth disturbance line after injury of the distal tibial physis. JBJS 1988 70B: 231-233.

2. Mann DC, Rajamaira S. Distribution of physeal and non physeal fractures in 2,650 long bone fractures in children 0-16 years. J Pediatr Orthop 1990 10:713-716.

3. Orava S, Saarela J. Exertion injuries to young athletes: a follow up research of orthopedic problems of young track and field athletes. Am J Sports Med 1978 6: 68-74.

4. Spiegel P, Cooperman D, Laros G. Epiphyseal fractures of the distal ends of the tibia and fibula. JBJS 1978 60A 1046-1059.

5. Poland J. Traumatic Separation of the Epiphysis. London; Smith, Elder \& Co, 1898. 
6. Ashhurst APC, Bromer RS. Classification and mechanism of fractures of the leg bones involving the ankle. Arch Surg 1922 4:51-129.

7. Kling T. Fractures of the ankle and foot. In: Drennan J (editor) The Child's Foot and Ankle. New York; Raven, 1992.

8. Caruthers CO, Crenshaw AH. Clinical significance of a classification of epiphyseal injuries at the ankle. Am J Surg 1955 89: 879-889.

9. Letts RM. The hidden adolescent ankle fractures J Pediatr Orthop 1982;2:161-164.

10. Herzenberg J. Computer tomography of pediatric distal tibial growth plate fracture: a practical guide. Tech Orthop 1989 4: 5364.

11. Kerr R, Forrester DM, Kingston S. Magnetic resonance imaging of foot and ankle trauma. Orthop Clin North Am 1990 21: 591-601.

12. Kay RM, Matthys GA. Pediatric ankle fractures: Evaluation and treatment. J Am Acad Orthop Surg 2001 9: 268-278.

13. Rohmiller MT, Gaynor TP, Pawelek J, Mubarak SJ. Salter-

Harris I and II fractures of the distal tibia: Does mechanism of injury relate to premature physeal closure? J Ped Ortho 2006 26(3): 322-328.

14. Dias LS, Tachdjian MO. Physeal injuries of the ankle in Children. Clinical Orthop 1978 136: 230-233.

15. Kling T. Fractures of the ankle and foot. In: Drennan J (editor) The Child's Foot and Ankle. New York; Raven, 1992. 16. Furia JP, Alioto RJ, Marquarrt JD. The efficacy and safety of the hematoma block for fracture reduction in closed, isolated fractures. Orthopedics 1997 20: 423-426.

17. Lehman W, Jones W. Intravenous lidocaine for anesthesia in the lower extremity. JBJS 1984 66A: 1056-1060. 